\title{
Comparison of Outcomes between Indirect Decompression of Oblique Lumbar Interbody Fusion and MIS-TLIF in One Single-level Lumbar Spondylosis: a case control study
}

\section{Shih-Feng Hung}

Chang Gung Memorial Hospital

Jen-chung Liao

Chang Gung Memorial Hospital

Tsung-Ting Tsai

Chang Gung Memorial Hospital

Yun-Da Li

Chang Gung Memorial Hospital

Ping-Yeh Chiu

Chang Gung Memorial Hospital

Ming-Kai Hsieh

Chang Gung Memorial Hospital

Fu-Cheng Kao ( $\square$ afogi73@gmail.com )

Chang Gung Memorial Hospital Linkou Branch https://orcid.org/0000-0001-5082-6650

Research article

Keywords:

Posted Date: June 19th, 2020

DOI: https://doi.org/10.21203/rs.3.rs-33673/v1

License: (c) (1) This work is licensed under a Creative Commons Attribution 4.0 International License. Read Full License 


\section{Abstract \\ Background}

Minimal invasive spinal fusion has become popular in the last decade. Oblique lumbar interbody fusion (OLIF) is a relatively new surgical technique and could avoid back muscle stripping and posterior complex destruction as in minimally invasive transforaminal lumbar interbody fusion (MIS-TLIF).

\section{Methods}

Between December 2016 and September 2018, patients with single level degenerative spondylosis were selected to enroll in this retrospective study.

\section{Results}

A total of 21 patients that underwent OLIF and 41 patients that received MIS-TLIF were enrolled. OLIF showed significantly less blood loss and shorter surgery time compared to MIS-TLIF $(p<0.05)$. The improvement in segmental lordosis and coronal balance was significantly more in OLIF group than MISTLIF group $(p<0.05)$. When comparing with MIS-TLIF, OLIF was significantly better in Oswestry Disability Index (ODI) and visual analogue scale for back pain improvement at post-operative 6 months $(p<0.05)$.

\section{Conclusions}

Both OLIF and MIS-TLIF are becoming a mainstream procedure for lumbar degenerative-related disease, especially for spondylolisthesis. However, OLIF has shown to have less perioperative blood loss and shorter surgery time than that of MIS-TLIF. In addition, OLIF gives superior clinical and radiographic outcomes. While both OLIF and MIS-TLIF provide optimal clinical outcomes, upon comparison between the two techniques, the anterolateral approach of OLIF seems to be a superior option in modern day.

\section{Background}

Many adults have experienced lower back pain at some point during their lifetime, and most of these symptoms resolve or improve without intervention within a few weeks. However, for a small number of these patients, lumbar fusion surgery may be required, especially when patients experience concomitant leg pain or deformity of lumbar body is present. Lumbar interbody fusion surgery is a treatment for lumbar spine-related disease including degenerative disc disease, spondylolisthesis, and disc herniation. The main objective of this technique is to create interbody fusion between two vertebral bodies in order to achieve a stable, decompressed vertebral structure. 
A variety of techniques of lumbar interbody fusion have been used to help alleviate pain from lumbar spine-related disease [1-3]. For the past few decades, the minimally invasive spinal surgical technique has emerged as an alternative approach to the more invasive open lumbar interbody fusion procedure [4-6]. The minimally invasive technique for transforaminal lumbar interbody fusion (MIS-TLIF) was first introduced in 2002, and it has since helped improve several perioperative outcomes including operative bleeding, infection incidence, surgical injury, and days of discharge [7-10].

Another technique called oblique lateral interbody fusion (OLIF) has been becoming more popular in the 21 st century. It offers solution to the potential surgical traumas caused by other conventional techniques by accessing lumbar disc through space between the aorta and psoas muscle[11]. This retroperitoneal lumbar approach, which was first coined in 2012, helps achieve indirect decompression and preserve integrity of posterior column structure[12].

Since OLIF is still a relatively new technique, there are only few studies that compare MIS-TLIF and OLIF based on their clinical and radiologic outcomes. The purpose of this study is to compare the radiographic and clinical outcomes between OLIF and MIS-TLIF in the patients with lumbar degenerative disease.

\section{Method}

\section{Study population and surgical techniques}

Between December 2016 and September 2018, a retrospective review was conducted from the spine department in our institution to identify all patients that underwent either OLIF or MIS-TLIF. Each surgical technique was performed by a single surgeon. Each patient in the MIS-TLIF group received unilateral MISTLIF surgery and was inserted a polyetheretherketone (PEEK) bullet-shaped cage that filled with autograft bone and demineralized bone matrix (Fig. 1). Posterior bilateral pedicle screw fixation was then applied. On the other hand, all patients in the OLIF group underwent anterolateral OLIF procedure used ORACLE cage (Depuy Company) that filled with cancellous allopathic bone graft (Fig. 2). Cage was inserted and lateral pedicle screws were then used for cage fixation.

Inclusion criteria for this study included patients with single lumbar level lesion (L2-L5) and had either degenerative spondylolisthesis, disc degeneration with vacuum phenomenon, neurogenic intermittent claudication, clinical sciatica, or mechanical low back pain with segmental instability. Exclusion criteria included spinal infection, spinal fracture, benign or malignant spinal tumor, revision surgery at the same level, and cervical or thoracic lesions and any patients with less than 2 years of follow-up. All patients included in this study had completed 2 follow-ups during the first 6 months (interval of 3 months) and then every half a year after for a minimum of 2 years. Other parameters recorded included age, sex, BMI, surgery time, blood loss, days of discharge, history of smoking, and history of diabetic mellitus. Medical records, laboratory data, radiographic images, and functional data of these patients were reviewed and analyzed. This study was approved by Chang Gung Medical Foundation Institutional Review Board (IRB), and the requirement for informed consent was waived due to the retrospective nature of the study. All 
procedures performed in this study were in accordance with the ethical standards of the national research committee.

\section{Clinical functioning}

Functional data for clinical outcomes were evaluated using visual analog scale (VAS) to assess lower back pain, leg pain, soreness, and the Oswestry Disability Index (ODI). The VAS evaluations were done at pre-operation, post-operation (3 days after surgery), and 6-months follow-up. The ODI assessments were done at pre-operation and 6-months follow-up.

\section{Radiography}

Radiographs of the patients were taken during pre-operation, immediate post-operation (3 days after surgery), and follow-ups. Measurements were taken for segmental lordotic angle (SLA), disc height (DH), cage subsidence (CS), screws halo sign (SHS), and coronal tilting angle (CTA). A single investigator measured SLA, DH, CTA, and their changes between pre-operation, post-operation, and follow-ups. SLA was obtained via lateral view of lumbar spine $x$-ray image by measuring the angle between upper end plate of vertebral body to lower endplate of lower vertebral body (Fig. 3). DH was defined as the distance from mid-position of upper endplate to lower endplate of two vertebral body (Fig. 3). CTA was assessed by measuring the Cobb angle of plane radiography of lumbar antero-posterior view (Fig. 4). The evaluations for SHS and CS were assessed 3 months after the surgery during the follow-up (Fig. 1F, 1G). CS was evaluated by measuring whether the cage migration was greater than 2-mm. Solid fusion status was defined as trabecular bone formation without gap between the vertebral endplate and the cage in the sagittal or coronal planes on radiograph; it was measured at one-year follow-up.

\section{Statistical Analysis}

Statistical calculations were performed using SPSS 25.0 to analyze the parameters in both groups of patients. All quantitative variables were presented as mean standard deviation, and qualitative variables were shown in terms of ratio and number. Continuous variables were evaluated by pooled t-test. The categorical variables were performed by Fisher exact test and Mann-Whitney test. A P value $<0.05$ was considered to be statistically significant difference.

\section{Result}

From December 2016 to September 2018, a total of 27 patients that underwent one single-level OLIF and 57 patients that received one single-level MIS-TLIF were selected. In the MIS-TLIF group, 16 patients were excluded from this study due to their surgical sites being at L5-S1. From the OLIF group, 3 patients were excluded because they had less than 2 years of follow-up and another 3 were excluded because they previously received either laminotomy or discectomy at the same level. After the screening, a total of 41 MIS-TLIF patients and 21 OLIF patients were selected to enroll in this study. 
The demographics for OLIF and MIS-TLIF groups were comparably matched. The mean ages (years) for MIS-TLIF and OLIF were 60.32 and 62.33, respectively $(p=0.5634)$. The mean BMI's $(\mathrm{kg} / \mathrm{m} 2)$ for MIS-TLIF and OLIF were 26.25 and 26.37 , respectively $(p=0.9179)$. Among the 41 MIS-TLIF patients, 8 of them had smoking history compared to 4 (out of 21 ) from the OLIF group $(p=0.965)$. Eight patients from the MISTLIF group had history of diabetic mellitus while the OLIF group had 4 patients $(p=0.965)$ (Table. 1$)$.

The average surgery time for OLIF was significantly shorter than that of MIS-TLIF $(93.95 \pm 14.84 \mathrm{vs}$ $136.38 \pm 31.18, p=0.0291$ ). The patients that received OLIF had fewer days of hospital discharge compared to the MIS-TLIF patients $(4.05 \pm 1.56$ vs $6.39 \pm 1.41, p<0.001)$. Blood loss during surgery was also significantly less in OLIF than in MIS-TLIF $(90.48 \pm 19.74 \mathrm{ml}$ vs $167.32 \pm 35.93 \mathrm{ml}, \mathrm{p}=0.0406)$ (Table. $3)$.

\section{Functional Outcomes}

Using the VAS pain score, the mean pre-operative back pain scores were relatively comparable between OLIF and MIS-TLIF ( $7 \pm 1.26$ vs6.61 $\pm 1.66, p=0.3563)$ (Table.2). The post-operative back pain scores were $1.05 \pm 0.94$ for OLIF and $7.56 \pm 1.18$ for MIS-TLIF $(p<0.0001)$. There was significant difference in back pain score between OLIF and MIS-TLIF for the 6-months follow up $(0.75 \pm 1.02$ vs $3.95 \pm 1.53, p<$ 0.0001 ). Pre-operative leg pain scores for OLIF and MIS-TLIF were $6 \pm 1.21$ and $6.32 \pm 2.01$, respectively $(p=0.4475)$; post-operative leg pain scores were $0.75 \pm 0.72$ and $0.85 \pm 0.88(p=0.6496)$. The preoperative ODI's were similar between the 2 groups (OLIF: $66.35 \pm 5.97$, MIS-TLIF: $69.71 \pm 7.24, p=$ 0.6532). The ODI improvement in follow-ups between the 2 groups showed significant difference (OLIF: $33.30 \pm 12.77$, MIS-TLIF: $21.51 \pm 9.94, p=0.026)$.

\section{Radiographic Outcomes}

The SLA increased from a mean of 11.75 preoperatively to 15.4 postoperatively in OLIF and MIS-TLIF showed a decrease from a mean of 17.12 preoperatively to 12.71 postoperatively (Table. 3 ). There was significant difference in the immediate SLA change between OLIF and MIS-TLIF ( $3.65 \pm 4.98$ vs $-4.41 \pm$ 7.94, $P=0.0098)$. The follow-up SLA decreased in both OLIF and MIST-TLIF (13.13 \pm 6.7 vs $11.43 \pm 5.89)$ and the difference in change was close to statistical significance $(P=0.0504)$. The CTA for OLIF was $6.62 \pm 4.01$ preoperatively, $1.93 \pm 1.48$ postoperatively, and $3.13 \pm 2.38$ follow-up; MIS-TLIF had CTA of $3.02 \pm 2.08$ preoperatively, $1.24 \pm 0.77$ postoperatively, and $1.81 \pm 0.92$ follow-up. Coronal tilting angle change (CTAC) did indicate a significant difference in both the immediate postoperative CTAC and follow up CTAC ( $p=0.0019,0.035$, respectively) between the 2 groups. The immediate disc height change (millimeters) was $3.44 \pm 1.41$ in OLIF and $2.99 \pm 1.53$ in MIS-TLIF. The follow up disc height changes (millimeters) for OLIF and MIS-TLIF were $2.34 \pm 1.05$ and $1.96 \pm 1.02$, respectively. Both the immediate disc height change and follow-up disc height change between the 2 groups showed no significant difference ( $p=0.2567,0.3152$, respectively). For fusion status, 16 out of 21 OLIF patients and 26 out of 41 MIS-TLIF patients showed complete union at the one-year follow-up $(p=0.312)$. Lastly, 5 out of 21 OLIF patients and 11 out of 41 MIS-TLIF patients showed post-operative CS and SHS $(p=0.7956)$. 


\section{Discussion}

OLIF and MIS-TLIF take different approaches. MIS-TLIF introduces direct spinal decompression through laminectomy and involves paraspinal access from posterolateral side of the lumbar intervertebral disc, which requires to some extent retraction of nerve roots and spinal erector muscles; however, major vessels like aorta can be unharmed. The posterior pedicle screw fixation is then used to provide mechanical support for the spine. On the other hand, OLIF accesses the space of lumbar disc by entering through the anatomical space between psoas muscle and aorta artery; one of the disadvantages of OLIF is iatrogenic vascular injury. OLIF mainly uses indirect decompression to alleviate compressed neural element, and many recent studies have shown promising results in anterolateral lumbar interbody fusion approach.

We want to compare the intraoperative data between OLIF and MIS-TLIF groups. Several literatures have pointed out that prolonged surgery time is associated with increased operative complication, and shorter operation time has positive impact on postoperative outcome. Less perioperative blood loss is also beneficial to patients, including reduced risk of exposure to pathogens, blood transfusion complication, perioperative anemia, morbidity, and mortality. In a recent systemic review on OLIF by Li et al., the 16 selected literatures showed a mean blood loss of $109.9 \mathrm{ml}$ and an average surgery time of 95.2 minutes [13]. Another retrospective study on MIS-TLIF with 20 patients enrolled by Lee et al. reported an average surgery time of 131.7 minutes and $208.3 \mathrm{ml}$ blood loss [14]. In our study, the average surgery time and perioperative blood loss for OLIF was significantly less than that of MIS-TLIF. While the surgery time and blood loss can vary depending on surgeon's expertise and repertoire, several studies have suggested that OLIF has superior perioperative results when comparing to MIS-TLIF. The OLIF's anterolateral approach allows surgeons to access surgical site through a small incision on the left lower abdomen where there are only few muscle layers that need to be retracted. Moreover, bony structural damage is avoided since laminectomy is not required in OLIF. The decrease in incidence of iatrogenic disturbance to the surrounding tissues and nerves ultimately yields better outcome in surgical bleeding and surgery time [15, 16]. Consequently, OLIF provides patients with better post-operative recovery and reduced risk of surgical complication.

Back muscles play vital roles in connecting multiple major muscles of human body parts, and OLIF allows back muscles to remain intact after surgery. By leaving the paraspinal muscles unharmed and with less soft tissue traction, patients are likely to have better post-operative recovery and shorter hospital stay. A retrospective study by Ohtori et al. investigated 35 patients that received OLIF, and the results demonstrated its effectiveness, with an average of 34 points improvement in ODI, 6.7 and 3.2 points decrease in VAS of leg and back, respectively [17]. According to several studies, a change of at least 15 points in ODI score and at least 3.5 points improvement in VAS can be an indicator to excellent operative outcome $[18,19]$. In our study, the average VAS pain scores and ODI reported by the patients showed clinically significant improvement in both groups. However, when comparing the outcome of the 2 groups, OLIF had the upper hand in the post-operative back pain improvement and days of hospital discharge. Shorter hospital stay means better immediate post-operative outcome and faster post-operative recovery. 
The absence of iatrogenic violation on the paraspinal elements may explain the low post-operative VAS and ODI scores in the OLIF group.

The sagittal balance is linked to better alignment of vertebral spine. The restoration of lumbar lordosis and disc height has been associated with better postoperative clinical outcomes. According to Videbaek et al., 92 patients with severe lower back pain were chosen for either posterolateral lumbar interbody fusion or anterior lumbar interbody fusion [20]. The sagittal balance parameters were analyzed. The result showed patients who had restored their sagittal balance had a significantly better clinical outcome measured by ODI. In our study, the OLIF group showed improvement in restoring segmental lordosis while the MIS-TLIF group had a decrease in segmental lordosis post-operatively. The reason for the decrease in segmental lordosis in the MIS-TLIF group was not clear, as patient-surgery interplay of multiple factors might have been involved, such as the bullet-shaped cage that was used in MIS-TLIF. For instance, in a study published by Gödde et al. a total of 42 patients that underwent posterior lumbar interbody fusion [21]. Twenty patients inserted with bullet-shaped cage had a mean decrease in segmental lordosis from $10^{\circ}$ to $2^{\circ}$ at L3-L4 and from $10^{\circ}$ to $5^{\circ}$ at L4-L5 while 22 patients inserted with wedge-shaped cage had an average increase in segment lordosis from $4^{\circ}$ to $7^{\circ}$ at L3-L4 and $2^{\circ}$ to $8^{\circ}$ at L4-L5. The cage geometry likely plays a role in alignment of lumbar spine after lumbar interbody fusion. There are several factors that can lead to kyphotic deformity at the fused segment after TLIF is done, including distraction due to pedicle screw insertion and the relative posterior location of the cage [22]. In addition, many studies on surgical outcomes of lumbar interbody fusion have suggested that having a cage covered in the anterior part of vertebral body could help with restoration of lumbar lordosis since the anterior portion of endplate is the strongest part [23-25]. This theory aligns with our result, as OLIF, with its wide cage being inserted in the relatively anterior part of vertebral body, showed better improvement in restoring segmental lordosis post-operatively. The cage's relative anterior location in OLIF helps provide better mechanical support [26]. Unlike that of MIS-TLIF, the pedicle screws in OLIF are used only for cage fixation rather than direct mechanical support. So theoretically speaking, the fact that OLIF uses wider cage and pedicle screws that don't bear as much stress as that of MIS-TLIF means OLIF patients could have less chance of cagesubsidence and screw halo sign post-operatively.

Coronal imbalance is not seen as a major surgical indication in most literatures. However, patients suffering from coronal imbalance tend to have increased pain, discomfort, and decreased the quality of daily life [27]. It is because, unlike sagittal malalignment, there are not many compensatory mechanisms available for coronal malalignment in a human body. Some studies have shown that coronal tilting angle can be corrected by oblique lumbar interbody fusion technique. In a study by Patel et al., 15 patients underwent OLIF and radiologic evaluation was done [28]. Cobb's angle, lumbar lordosis, sagittal vertical axis, thoracic kyphosis, sacral slope, pelvic tilt, and pelvic incidence all showed significant correction immediately after the procedure. All the parameters except thoracic kyphosis were maintained at the last follow-up. In another study by Wang et al., 11 patients with lumbar degenerative disease underwent a combination of OLIF and lateral fixation [29]. Radiographic results showed significant improvement in coronal Cobb angle from $15.3^{\circ}$ pre-operatively to $5.9^{\circ}$ post-operatively. OLIF procedure is capable of restoring the global and sagittal spinal alignment via leveling the vertebrae and disc space intended to 
fuse. Furthermore, Temple et al. suggested that lateral fixation with pre-bent rod could accomplish further sagittal and coronal plane correction [30]. In our study, while both groups showed improvement in coronal tilting angle, the OLIF group showed significant difference in reduction of coronal tilting angle in postoperation and follow-ups compared to that of MIS-TLIF. Like previously mentioned, MIS-TLIF uses a smaller bullet-shaped cage that is inserted in the central part of the vertebral body. On the other hand, OLIF uses a larger cage that is inserted in the anterior part of the vertebral body, which gives stronger and more evenly support to the spine. This may explain the edge that OLIF had over MIS-TLIF in coronal balance correction in our study.

There are still some limitations in this study. First of all, it was a retrospective study with relatively small sample size. In addition, the samples were not randomized, which may have resulted in selection bias. Secondly, each surgical technique was performed by one surgeon. The skillsets and experience of each surgeon could have some impact on the results. Lastly, the radiographic measurements were done by a single observer, which may have some intra-observer bias.

\section{Conclusion}

Both OLIF and MIS-TLIF are mainstream procedures for lumbar degenerative-related disease. While both OLIF and MIS-TLIF provide optimal clinical outcomes, OLIF has shown superior clinical and radiographic outcomes compared to MIS-TLIF. Upon comparison between the two techniques, the anterolateral approach of OLIF seems to be a better option in modern day.

\section{Abbreviations}

OLIF

oblique lumbar interbody fusion

MIS TLIF

minimally invasive transforaminal lumbar interbody fusion

PEEK

polyetheretherketone

$\mathrm{BMI}$

body mass index

IRB

Institutional Review Board

VAS

visual analog scale

ODI

oswestry disability index

SLA

segmental lordotic angle

$\mathrm{DH}$ 
disc height

CS

cage subsidence

SHS

screws halo sign

CTA

coronal tilting angle

SPSS

statistical product and service solutions

CTAC

coronal tilting angle change

\section{Declarations}

\section{Ethics approval and consent to participate:}

not applicable

Consent for publication:

not applicable

\section{Availability of data and materials:}

The datasets generated and/or analysed during the current study are available from the corresponding author on reasonable request.

Competing interests:

The authors declare that they have no competing interests

\section{Funding:}

There is no funding source.

\section{Authors' contributions:}

WJ Chen made substantial contributions to conception, study design and analysis and interpretation of data. FC Kao and MK Hsieh analyzed and collected the patient data and were major contributors in writing the manuscript. All authors read and approved the final manuscript. 


\section{Acknowledgements:}

Not applicable

\section{Conflict of Interest:}

Each author certifies that he has no commercial associations.

\section{Disclosure of Funding}

None.

\section{References}

1. Blumenthal SL, Baker J, Dossett A, Selby DK. The role of anterior lumbar fusion for internal disc disruption. Spine (Phila Pa 1976). 1988;13(5):566-9.

2. Harms J, Rolinger $\mathrm{H}$. [A one-stager procedure in operative treatment of spondylolistheses: dorsal traction-reposition and anterior fusion (author's transl)]. Z Orthop Ihre Grenzgeb. 1982;120(3):343-7.

3. Campbell PG, Nunley PD, Cavanaugh D, Kerr E, Utter PA, Frank K, Stone M. Short-term outcomes of lateral lumbar interbody fusion without decompression for the treatment of symptomatic degenerative spondylolisthesis at L4-5. Neurosurg Focus. 2018;44(1):E6.

4. Ucar BY, Ozcan C, Polat O, Aman T. Transforaminal Lumbar Interbody Fusion For Lumbar Degenerative Disease: Patient Selection And Perspectives. Orthop Res Rev. 2019;11:183-9.

5. Mobbs RJ, Phan K, Malham G, Seex K, Rao PJ. Lumbar interbody fusion: techniques, indications and comparison of interbody fusion options including PLIF, TLIF, MI-TLIF, OLIF/ATP, LLIF and ALIF. J Spine Surg. 2015;1(1):2-18.

6. Park Y, Ha JW. Comparison of one-level posterior lumbar interbody fusion performed with a minimally invasive approach or a traditional open approach. Spine (Phila Pa 1976). 2007;32(5):53743.

7. Foley KT, Lefkowitz MA. Advances in minimally invasive spine surgery. Clin Neurosurg. 2002;49:499517.

8. Foley KT, Holly LT, Schwender JD. Minimally invasive lumbar fusion. Spine (Phila Pa 1976). 2003;28(15 Suppl):26-35.

9. Schwender JD, Holly LT, Rouben DP, Foley KT. Minimally invasive transforaminal lumbar interbody fusion (TLIF): technical feasibility and initial results. J Spinal Disord Tech. 2005;18 Suppl:1-6.

10. Scheufler KM, Dohmen H, Vougioukas VI. Percutaneous transforaminal lumbar interbody fusion for the treatment of degenerative lumbar instability. Neurosurgery. 2007;60(4 Suppl 2):203-12. discussion $212-203$.

11. Molinares DM, Davis TT, Fung DA. Retroperitoneal oblique corridor to the L2-S1 intervertebral discs: an MRI study. J Neurosurg Spine. 2016;24(2):248-55. 
12. Silvestre C, Mac-Thiong JM, Hilmi R, Roussouly P. Complications and Morbidities of Mini-open Anterior Retroperitoneal Lumbar Interbody Fusion: Oblique Lumbar Interbody Fusion in 179 Patients. Asian Spine J. 2012;6(2):89-97.

13. Li JX, Phan K, Mobbs R. Oblique Lumbar Interbody Fusion: Technical Aspects, Operative Outcomes, and Complications. World Neurosurg. 2017;98:113-23.

14. Lee CK, Park JY, Zhang HY. Minimally invasive transforaminal lumbar interbody fusion using a single interbody cage and a tubular retraction system: technical tips, and perioperative, radiologic and clinical outcomes. J Korean Neurosurg Soc. 2010;48(3):219-24.

15. Mehren C, Korge A. Minimally invasive anterior oblique lumbar interbody fusion (OLIF). Eur Spine J. 2016;25(Suppl 4):471-2.

16. Fujibayashi S, Hynes RA, Otsuki B, Kimura H, Takemoto M, Matsuda S. Effect of indirect neural decompression through oblique lateral interbody fusion for degenerative lumbar disease. Spine (Phila Pa 1976). 2015;40(3):E175-82.

17. Ohtori S, Orita S, Yamauchi K, Eguchi Y, Ochiai N, Kishida S, Kuniyoshi K, Aoki Y, Nakamura J, Ishikawa T, et al. Mini-Open Anterior Retroperitoneal Lumbar Interbody Fusion: Oblique Lateral Interbody Fusion for Lumbar Spinal Degeneration Disease. Yonsei Med J. 2015;56(4):1051-9.

18. Copay AG, Cher DJ. Is the Oswestry Disability Index a valid measure of response to sacroiliac joint treatment? Qual Life Res. 2016;25(2):283-92.

19. Glassman S, Gornet MF, Branch C, Polly D Jr, Peloza J, Schwender JD, Carreon L. MOS short form 36 and Oswestry Disability Index outcomes in lumbar fusion: a multicenter experience. Spine J. 2006;6(1):21-6.

20. Videbaek TS, Bunger CE, Henriksen M, Neils E, Christensen FB: Sagittal spinal balance after lumbar spinal fusion: the impact of anterior column support results from a randomized clinical trial with an eight- to thirteen-year radiographic follow-up. Spine (Phila Pa 1976) 2011, 36(3):183-191.

21. Godde S, Fritsch E, Dienst M, Kohn D. Influence of cage geometry on sagittal alignment in instrumented posterior lumbar interbody fusion. Spine (Phila Pa 1976). 2003;28(15):1693-9.

22. Kim SB, Jeon TS, Heo YM, Lee WS, Yi JW, Kim TK, Hwang CM. Radiographic results of single level transforaminal lumbar interbody fusion in degenerative lumbar spine disease: focusing on changes of segmental lordosis in fusion segment. Clin Orthop Surg. 2009;1(4):207-13.

23. Kwon BK, Berta S, Daffner SD, Vaccaro AR, Hilibrand AS, Grauer JN, Beiner J, Albert TJ. Radiographic analysis of transforaminal lumbar interbody fusion for the treatment of adult isthmic spondylolisthesis. J Spinal Disord Tech. 2003;16(5):469-76.

24. Ko MJ, Park SW, Kim YB. Effect of Cage in Radiological Differences between Direct and Oblique Lateral Interbody Fusion Techniques. J Korean Neurosurg Soc. 2019;62(4):432-41.

25. Tatsumi R, Lee YP, Khajavi K, Taylor W, Chen F, Bae H. In vitro comparison of endplate preparation between four mini-open interbody fusion approaches. Eur Spine J. 2015;24(Suppl 3):372-7.

26. Lin GX, Akbary K, Kotheeranurak V, Quillo-Olvera J, Jo HJ, Yang XW, Mahatthanatrakul A, Kim JS. Clinical and Radiologic Outcomes of Direct Versus Indirect Decompression with Lumbar Interbody 
Fusion: A Matched-Pair Comparison Analysis. World Neurosurg. 2018;119:e898-909.

27. Obeid I, Berjano P, Lamartina C, Chopin D, Boissiere L, Bourghli A. Classification of coronal imbalance in adult scoliosis and spine deformity: a treatment-oriented guideline. Eur Spine J. 2019;28(1):94113.

28. Patel RS, Suh SW, Kang SH, Nam KY, Siddiqui SS, Chang DG, Yang JH. The Radiologic and Clinical Outcomes of Oblique Lateral Interbody Fusion for Correction of Adult Degenerative Lumbar Deformity. Indian J Orthop. 2019;53(4):502-9.

29. Wang K, Zhang C, Cheng C, Jian F, Wu H. Radiographic and Clinical Outcomes following Combined Oblique Lumbar Interbody Fusion and Lateral Instrumentation for the Treatment of Degenerative Spine Deformity: A Preliminary Retrospective Study. Biomed Res Int. 2019;2019:5672162.

30. Tempel ZJ, Gandhoke GS, Bonfield CM, Okonkwo DO, Kanter AS. Radiographic and clinical outcomes following combined lateral lumbar interbody fusion and posterior segmental stabilization in patients with adult degenerative scoliosis. Neurosurg Focus. 2014;36(5):E11.

\section{Tables}

Table 1

Demographic parameters

\begin{tabular}{|c|c|c|c|}
\hline \multicolumn{2}{|l|}{ MIS-TLIF } & \multirow{2}{*}{$\begin{array}{l}\text { OLIF } \\
21\end{array}$} & \multirow[t]{2}{*}{ p-value } \\
\hline Number of patients & 41 & & \\
\hline Age & $60.32 \pm 13.34$ & $62.33 \pm 12.08$ & 0.5634 \\
\hline Sex (Male: Female) & $28: 13$ & 10:11 & 0.1137 \\
\hline Smoker & 8 & 4 & 0.965 \\
\hline $\mathrm{BMI}\left(\mathrm{kg} / \mathrm{m}^{2}\right)$ & $26.25 \pm 3.96$ & $26.37 \pm 4.43$ & 0.9179 \\
\hline Diabetic Mellitus & 8 & 4 & 0.965 \\
\hline \multicolumn{4}{|c|}{$\begin{array}{l}\text { Values are mean } \pm \text { standard deviation; OLIF: oblique lateral lumbar interbody fusion; MI-TLIF: } \\
\text { minimally invasive transforaminal lumbar interbody fusion; BMl: body mass index } \\
\star:: p<0.05 \text {, statistical significance }\end{array}$} \\
\hline
\end{tabular}


Table 2

Perioperative and clinical outcomes

\begin{tabular}{|llll|}
\hline MIS-TLIF & & OLIF & p-value \\
\hline Blood loss & $167.32 \pm 35.93$ & $90.48 \pm 19.74$ & $0.0406^{*}$ \\
\hline Surgery time & $136.38 \pm 31.18$ & $93.95 \pm 14.84$ & $0.0291^{*}$ \\
\hline Days of discharge & $6.39 \pm 1.41$ & $4.05 \pm 1.56$ & $<0.0001^{*}$ \\
\hline Pre VAS back pain & $6.61 \pm 1.66$ & $7 \pm 1.26$ & 0.3563 \\
\hline Post VAS back pain & $7.56 \pm 1.18$ & $1.05 \pm 0.94$ & $<0.0001^{*}$ \\
\hline F/U VAS back pain & $3.95 \pm 1.53$ & $0.75 \pm 1.02$ & $<0.0001^{*}$ \\
\hline Pre VAS leg pain & $6.32 \pm 2.01$ & $6 \pm 1.21$ & 0.4475 \\
\hline Post VAS leg pain & $0.85 \pm 0.58$ & $0.75 \pm 0.62$ & 0.6496 \\
\hline Pre ODI & $69.71 \pm 7.24$ & $66.35 \pm 5.97$ & 0.6532 \\
\hline Follow-up ODI & $48.2 \pm 5.93$ & $33.05 \pm 9.96$ & $<0.0001^{*}$ \\
\hline $\begin{array}{l}\text { ODI improvement } \\
\text { Values are mean } \pm \text { standard deviation; ODI: Oswestry Disability Index; VAS: visual analogue scale; }\end{array}$ & \\
\hline $\begin{array}{l}\text { Post: pos-operative (3 days after surgery); F/U: follow-up (6 months after surgery) } \\
\text { *: } \text { P }<\text { 0.05, statistical significance }\end{array}$ & & \\
\hline
\end{tabular}


Table 3

Radiographic outcomes

\begin{tabular}{|c|c|c|c|c|}
\hline \multicolumn{3}{|l|}{ MIS-TLIF } & OLIF & p-value \\
\hline \multicolumn{2}{|l|}{ Pre SLA } & $17.12 \pm 8.73$ & $11.75 \pm 6.18$ & 0.1014 \\
\hline \multicolumn{2}{|l|}{ Post SLA } & $12.71 \pm 5.38$ & $15.4 \pm 7.53$ & 0.1093 \\
\hline \multicolumn{2}{|l|}{ F/U SLA } & $11.43 \pm 5.89$ & $13.13 \pm 6.7$ & 0.3411 \\
\hline \multicolumn{2}{|l|}{ Post SLA change } & $-4.41 \pm 7.94$ & $3.65 \pm 4.98$ & $0.0098 *$ \\
\hline \multicolumn{2}{|l|}{ F/U SLA change } & $-5.69 \pm 8.19$ & $1.38 \pm 4.54$ & 0.0504 \\
\hline \multicolumn{2}{|l|}{ Pre CTA } & $3.02 \pm 2.08$ & $6.62 \pm 4.01$ & $0.0007 *$ \\
\hline \multicolumn{2}{|l|}{ Post CTA } & $1.24 \pm 0.77$ & $1.93 \pm 1.48$ & 0.0583 \\
\hline \multicolumn{2}{|l|}{ F/U CTA } & $1.81 \pm 0.92$ & $3.13 \pm 2.38$ & $0.0350 *$ \\
\hline \multicolumn{2}{|l|}{ Post CTA change } & $-1.78 \pm 1.13$ & $-4.69 \pm 3.59$ & $0.0019 *$ \\
\hline \multicolumn{2}{|l|}{ F/U CTA change } & $-1.21 \pm 1.87$ & $-3.49 \pm 3.03$ & $0.0014^{*}$ \\
\hline \multicolumn{2}{|l|}{ Pre disc height } & $7.38 \pm 1.76$ & $7.08 \pm 1.77$ & 0.5255 \\
\hline \multicolumn{2}{|l|}{ Post disc height } & $10.37 \pm 1.11$ & $10.52 \pm 1.4$ & 0.6316 \\
\hline \multicolumn{2}{|l|}{ F/U disc height } & $9.34 \pm 1.12$ & $9.42 \pm 0.81$ & 0.7894 \\
\hline \multicolumn{2}{|l|}{ Post disc height change } & $2.99 \pm 1.53$ & $3.44 \pm 1.41$ & 0.2567 \\
\hline \multicolumn{2}{|l|}{ F/U disc height change } & $1.96 \pm 1.02$ & $2.34 \pm 1.05$ & 0.3152 \\
\hline \multirow[t]{2}{*}{ Post cage subsidence } & Yes & 11 & 5 & \multirow[t]{2}{*}{0.7956} \\
\hline & No & 30 & 16 & \\
\hline \multirow[t]{2}{*}{ Post halo sign } & Yes & 11 & 5 & \multirow[t]{2}{*}{0.7956} \\
\hline & No & 30 & 16 & \\
\hline \multirow[t]{2}{*}{ Fusion status } & Solid & 26 & 16 & \multirow[t]{2}{*}{0.3120} \\
\hline & Incomplete & 15 & 5 & \\
\hline \multicolumn{5}{|c|}{$\begin{array}{l}\text { Values are mean } \pm \text { standard deviation; SLA: segmental lordotic angle; CTA: coronal tilting angle; Post } \\
\text { post-operative ( } 3 \text { days after surgery); F/U: follow-up } \\
\star:: p<0.05 \text {, statistical significance }\end{array}$} \\
\hline
\end{tabular}

Figures 


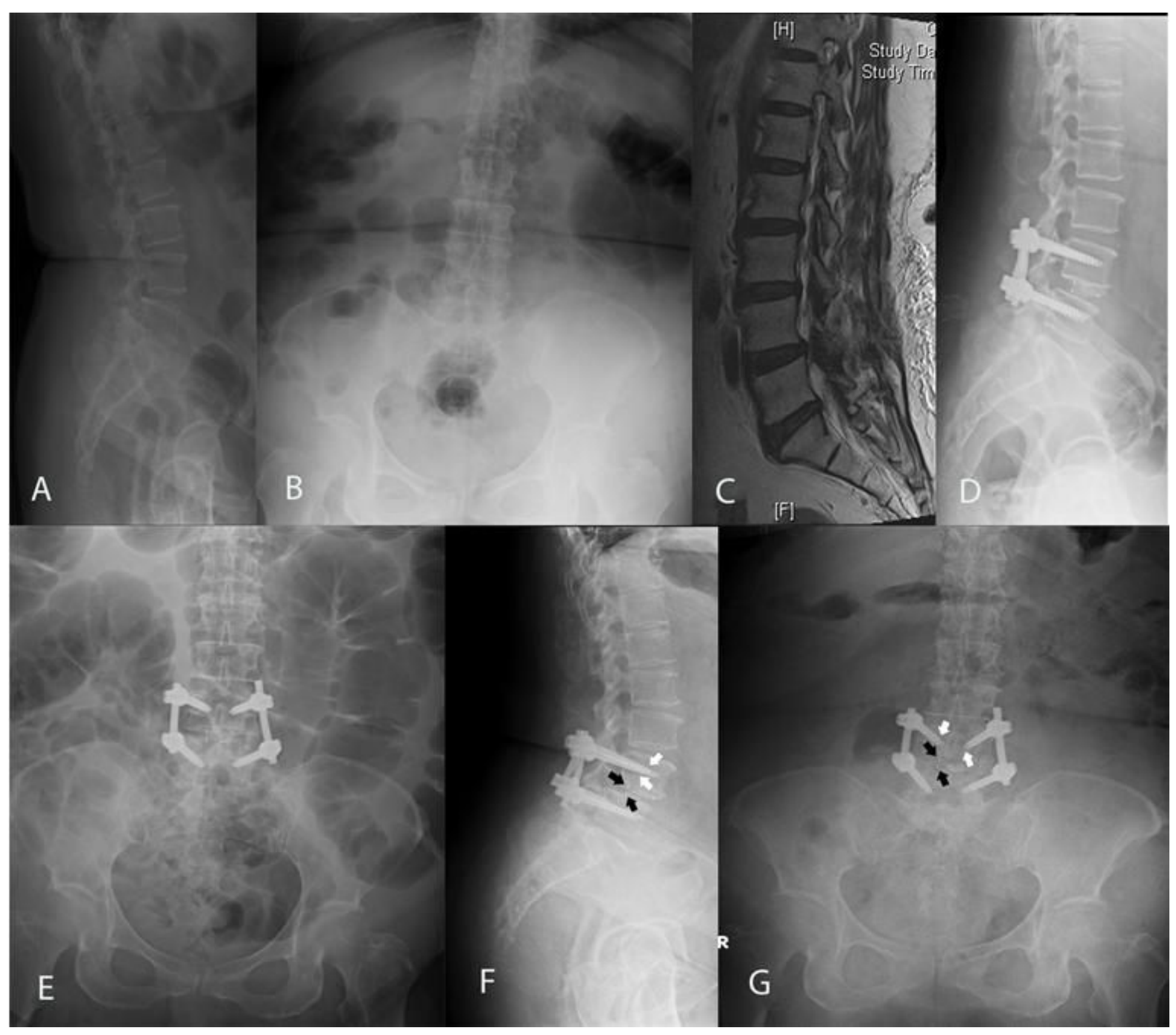

\section{Figure 1}

A 67-year-old female was diagnosed preoperatively with degenerative spondylolisthesis and lumbar spinal stenosis at L4-5 level, and underwent minimally invasive transforaminal lumbar interbody fusion (MIS-TLIF). Radiographic images $(A, B)$ and MRI $(C)$ were taken preoperatively. The immediate postoperative lumbar spine lateral view (D) and lumbar antero-posterior view (E) are shown. Cage subsidence (black arrow) and screw halo sign (white arrow) were seen on the one-year follow-up images $(F, G)$. 


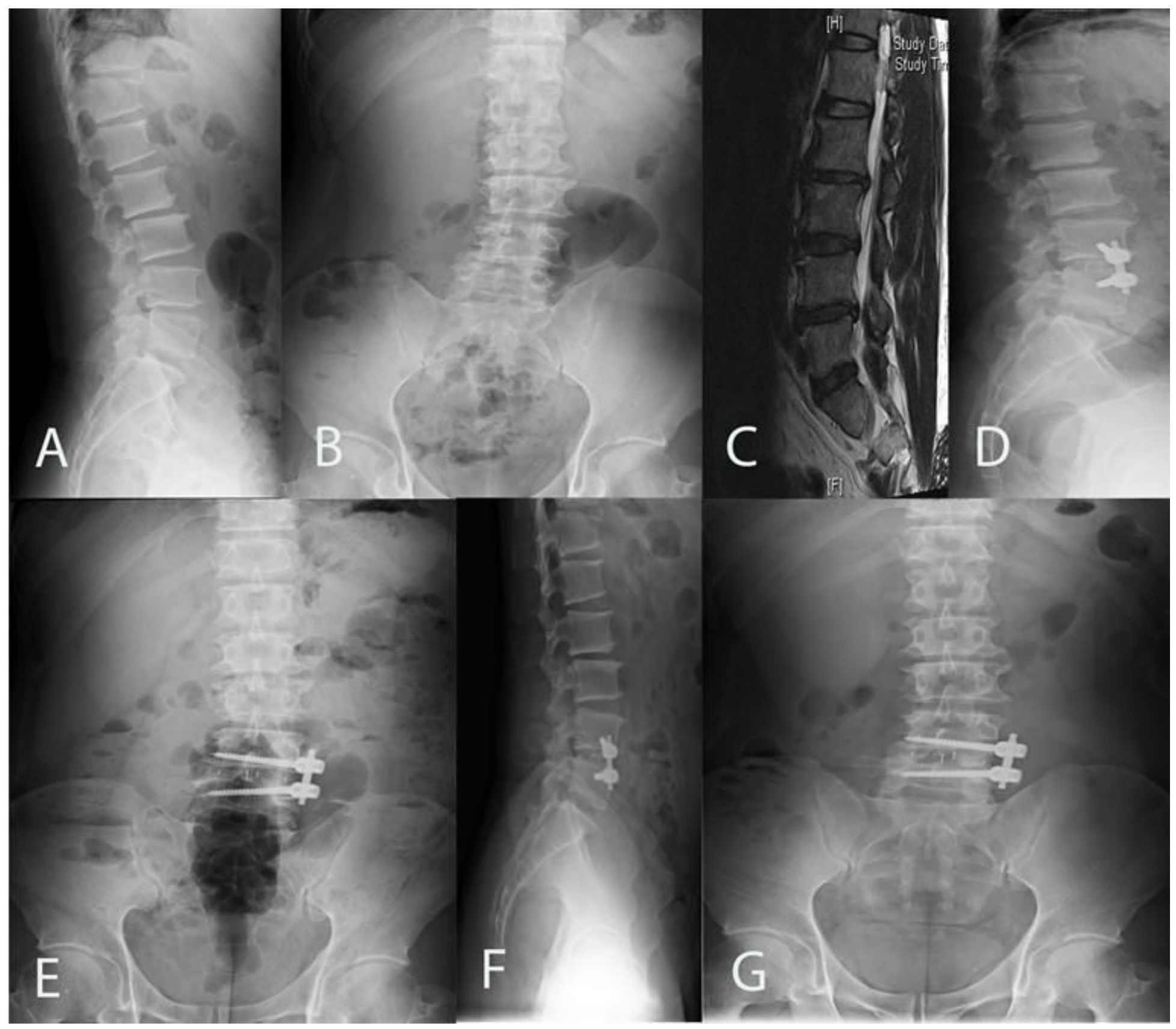

Figure 2

A 47-year-old man was diagnosed with degenerative spondylolisthesis and lumbar spinal stenosis at L4-5 level, as shown on lumbar spine lateral view (A), lumbar antero-posterior view (B), and T2-weighted MR image (C). He received oblique lumbar interbody fusion (OLIF) at L4-L5 with lumbar spine lateral view (D) and lumbar antero-posterior view images $(\mathrm{E})$ taken immediately after the surgery. Follow-up images $(\mathrm{F}, \mathrm{G})$ were taken at one-year follow-up. 


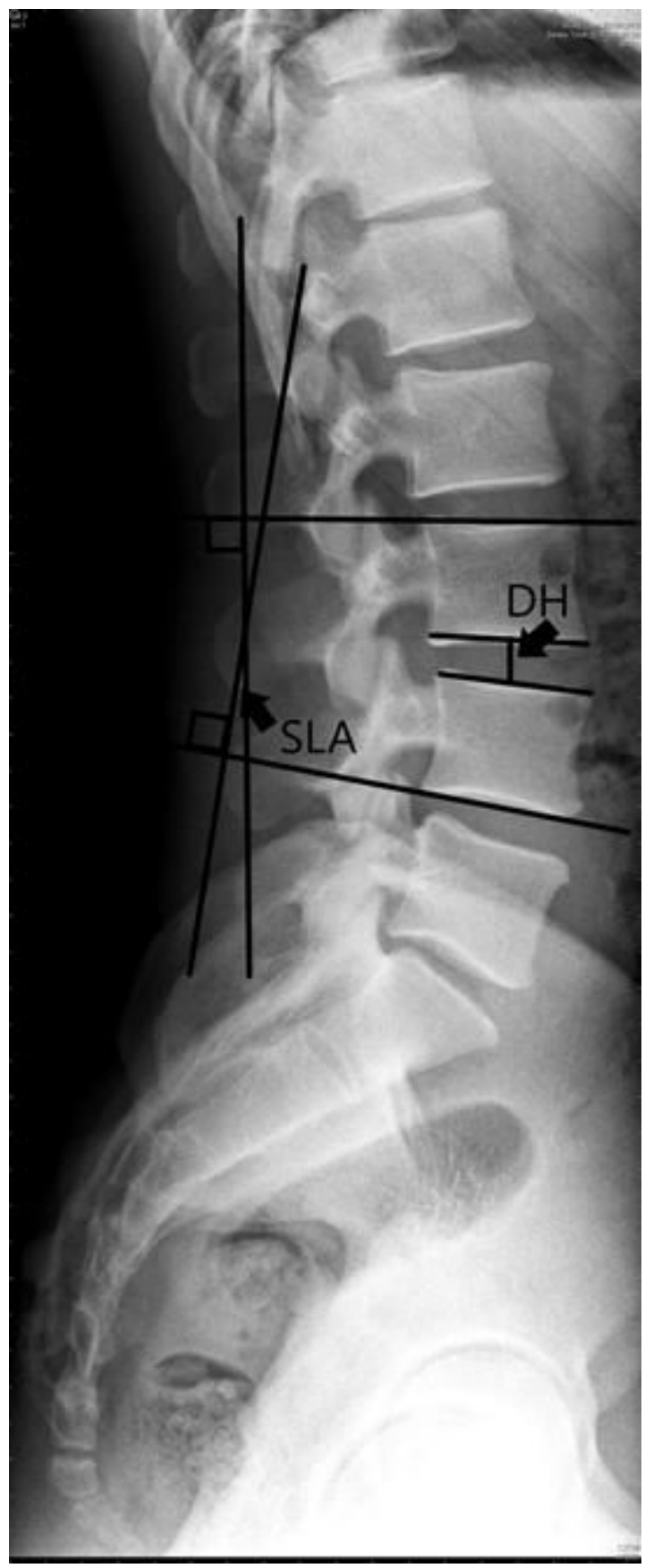

Figure 3

A 29-year-old male without any underlying disease had his segmental lordotic angle and disc height measured at L3-L4 on his lumbar spine lateral view image. Segmental lordotic angle (SLA) is defined as the angle subtended by the superior endplate line of upper vertebral body and the lower endplate of lower vertebral body. Disc Height (DH) is defined as the distance from mid-position of upper endplate to lower endplate of two vertebral body. 


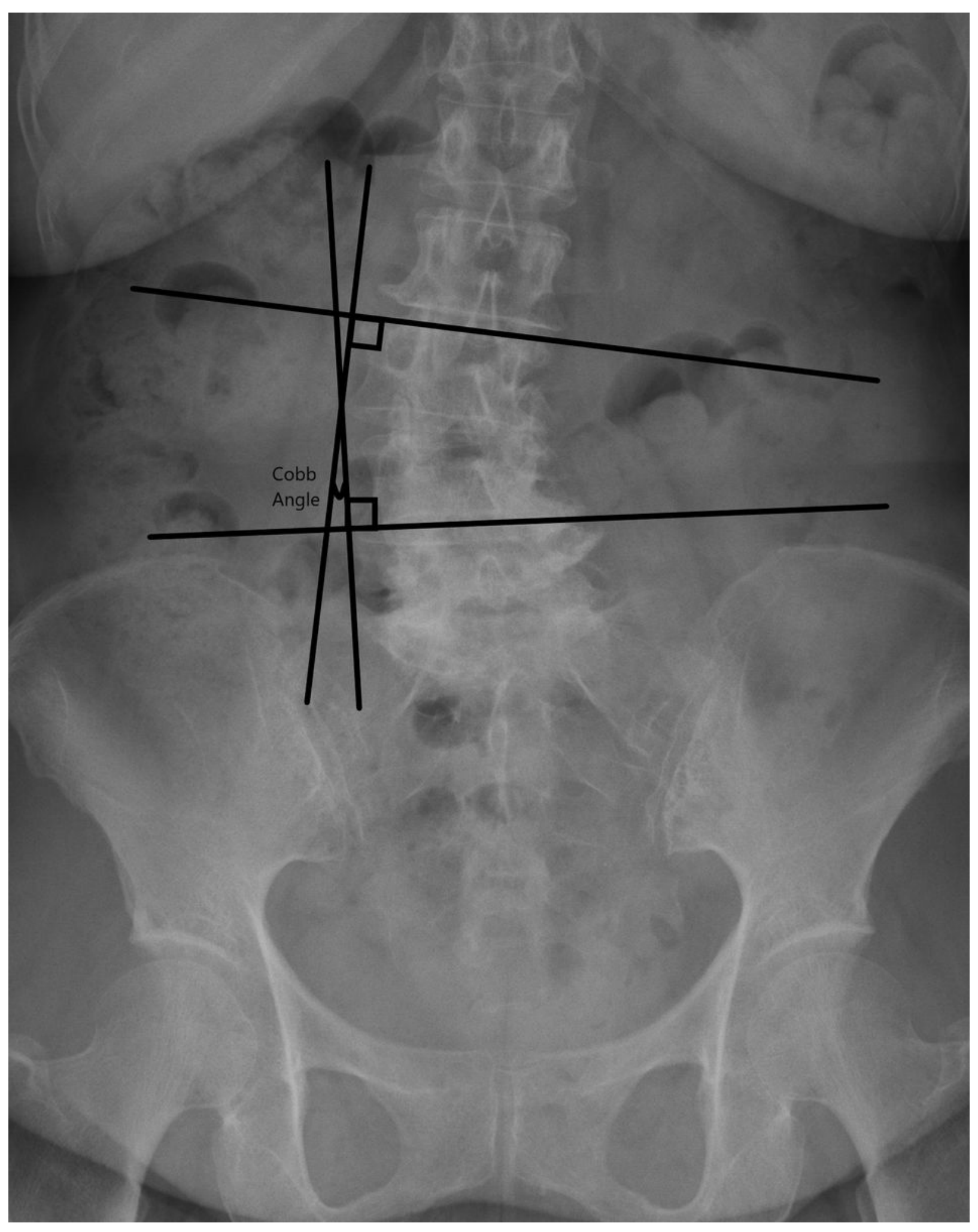

\section{Figure 4}

A 72-year-old female with degenerative spondylolisthesis and lumbar spinal stenosis had her coronal tilting angle measured at L3-L4 on lumbar antero-posterior view image. Measure of coronal tilting angle was assessed by measuring Cobb angle of superior endplate line of upper vertebral body and the lower endplate of lower vertebral body on lumbar antero-posterior view image. 